\title{
Long-term effects of postpartum clinical disease on milk production, reproduction, and culling of dairy cows
}

\author{
M. R. Carvalho, ${ }^{1}$ F. Peñagaricano, ${ }^{2}$ J. E. P. Santos, ${ }^{2}$ T. J. DeVries, ${ }^{1}$ B. W. McBride, ${ }^{1}$ and E. S. Ribeiro ${ }^{1 *}$ \\ ${ }^{1}$ Department of Animal Biosciences, University of Guelph, ON, Canada, N1G 2W1 \\ ${ }^{2}$ Department of Animal Sciences, University of Florida, Gainesville 32611
}

\begin{abstract}
Two retrospective studies examining data of 7,500 lactating cows from a single herd were performed with the objective of evaluating the long-term effects of clinical disease during the early postpartum period on milk production, reproduction, and culling of dairy cows through 305 days in milk (DIM). In the first study, data regarding health, milk production, reproduction, and culling of 5,085 cows were summarized. Cows were classified according to incidence of clinical problem (metritis, mastitis, lameness, digestive problem, or respiratory problem) during the first 21 DIM (ClinD21). During $305 \mathrm{~d}$ of lactation, cows that had ClinD21 produced, on average, $410 \mathrm{~kg}$ less milk, $17 \mathrm{~kg}$ less fat, and $12 \mathrm{~kg}$ less protein compared with cows that did not have ClinD21 (NoClinD21). Although the interval to first breeding was not different between groups of interest, pregnancy rate through 305 DIM was lower in cows that had ClinD21 [adjusted hazard ratio $(\mathrm{AHR})=$ 0.81]. When individual breedings were analyzed, cows that had ClinD21 presented lower rates of pregnancy per breeding for breedings performed before 150 DIM, reduced numbers of calving per breeding for breedings performed before 200 DIM, and greater number of pregnancy losses for all breedings performed through 305 DIM. The rate of culling from calving through 305 DIM was higher in cows that had a single ClinD21 $(\mathrm{AHR}=1.79)$ and in cows that had multiple ClinD21 $(\mathrm{AHR}=3.06)$, which resulted in a greater proportion of cows leaving the herd by 305 DIM (NoClinD21 = $22.6 \%$; single ClinD21 $=35.7 \%$; multiple ClinD21 $=$ $53.8 \%$ ). In the second study, data regarding postpartum health and 305-d yields of milk, fat, and protein were collected from 2,415 primiparous cows that had genomic testing information. Genomic estimated breeding values (EBV) were used to predict $305-\mathrm{d}$ yields of
\end{abstract}

Received May 26, 2019.

Accepted July 29, 2019.

*Corresponding author: eribeiro@uoguelph.ca milk, fat, and protein. Genomic EBV and predicted yields of milk, fat, and protein did not differ between cows that had ClinD21 and those that did not have ClinD21. In contrast, the observed 305-d yields of milk, fat, and protein were reduced by 345,10 , and $10 \mathrm{~kg}$, respectively, in cows that had ClinD21 compared with cows that did not have ClinD21. We conclude that clinical disease diagnosed and treated during the first 21 DIM has long-term effects on lactation performance, reproduction, and culling of dairy cows, which contribute to detrimental consequences of health problems on sustainability of dairy herds. Replication of our studies in multiple herds will be important to confirm our findings in a larger population.

Key words: clinical disease, dairy cow, lactation, reproduction, culling

\section{INTRODUCTION}

The susceptibility of dairy cows to health disorders is amplified during the early postpartum period. The nutritional deficit and resulting postpartum metabolic scenario impair function of immune cells and increase the vulnerability to opportunistic microbial infections (Sordillo, 2016). In addition, the enlarged postpartum uterus, filled with placenta remnants and lochia, favors proliferation of microbes and development of uterine infections (Sheldon et al., 2009). Recently, Ribeiro and Carvalho (2017) compiled information from multiple studies and reported that approximately one-third of dairy cows have at least 1 clinical disease (metritis, mastitis, digestive problem, respiratory problem, or lameness) during the first $3 \mathrm{wk}$ of lactation.

Clinical diseases have negative consequences for the economics of dairy farms (Galligan, 2006) and the welfare of dairy cows (Sumner et al., 2018). Costs associated with diagnosis, treatment, labor, infrastructure, and logistics needed to work with diseased cows are part of the direct costs associated with clinical diseases in a dairy farm. In addition, most cows with clinical health problems have reduced milk production, and in some cases the harvested milk has to be discarded because of 
treatment residues. Nonetheless, besides the immediate economic losses, clinical diseases seem to have longterm effects on the physiology of dairy cows that compromise performance even after clinical recovery from health problems, which contribute significantly to the overall costs of clinical diseases (Ribeiro et al., 2016). For instance, cows diagnosed with at least one postpartum clinical disease have reduced fertility at the first postpartum breeding, which occurs approximately 8 to 10 wk after clinical resolution of the health problem (Santos et al., 2010; Ribeiro et al., 2013, 2016; Ribeiro and Carvalho, 2017).

It remains unclear, however, how long the consequences of clinical diseases last after clinical resolution and whether the long-term consequences are limited to reproduction or may also be observed in other biological systems. Knowing the complete consequences of clinical diseases is critical to measure their effects on the profitability and sustainability of dairy farms, and should influence perceptions of the problem by stakeholders of the dairy industry. Moreover, knowing the duration of the detrimental consequences of clinical diseases provides valuable information for management decisions related to culling and breeding.

The objective of study 1 was to evaluate the effects of clinical diseases diagnosed and treated during the early postpartum period on milk production, reproduction, and culling of dairy cows through 305 DIM. We hypothesized that clinical disease during the early postpartum period has long-lasting detrimental consequences on lactation and reproductive performances and, consequently, increases the rate of culling of lactating cows. The objective of study 2 was to investigate the association between lactation performance, clinical diseases during the early postpartum period, and genetic merit for production traits. We hypothesized that the genetic merit for milk production traits in cows that had or did not have postpartum disease would not differ, and the differences in lactation performance between healthy and diseased groups could be attributed to long-term consequences of disease and not to genetic differences.

\section{MATERIALS AND METHODS}

\section{Study 1}

Animals, Housing, and General Management. This retrospective cohort study examined data of all cows that calved in a large dairy operation located in Florida during the year 2012. At the time of the study, the farm consisted of 5,000 lactating Holstein cows, and the rolling herd average milk production was approximately 11,000 kg. Primiparous and multiparous cows were housed separately in freestall barns equipped with tunnel ventilation and sand-bedded stalls. Feed was delivered twice daily as a TMR, formulated to meet the nutrient requirements of lactating cows producing 45 $\mathrm{kg}$ of milk per day according to the NRC (2001). Cows were milked 3 times daily, and yields of milk were recorded at each milking (SmartDairy meter, Boumatic, Madison, WI). Official milk tests of the DHIA were performed monthly. Cows were managed according to standard operating procedures, and all management procedures were performed by trained personnel and supervised by the herd veterinarians and the University of Florida Food Animal Reproduction and Medicine Service.

Study Design. Detailed information regarding health, production, reproduction, and culling from the day of calving through 305 DIM were collected from 5,085 Holstein cows (1,814 primiparous and 3,271 multiparous). All events and their dates of occurrence were retrieved from the management computer software of the dairy (PCDART, DRMS, Raleigh, NC). Cows were classified according to incidence of clinical disease during the first 21 DIM as (1) cows without clinical disease (NoClinD21) or (2) cows with at least one clinical disease (ClinD21). In addition, cows with ClinD21 were further classified according to the number of ClinD21, as single or multiple ClinD21. The effects of the incidence and the number of ClinD21 on incidence of clinical disease after 21 DIM, yield and composition of milk, reproduction, and culling through 305 DIM were then evaluated. For all outcomes, the effects of uterine disease (UTD) and non-uterine disease (NUTD), individually or combined, were also evaluated. Clinical diseases considered were retained placenta, metritis, clinical mastitis, lameness, digestive problems, and respiratory problems. Retained placenta and metritis, alone or combined, were always counted as one UTD because cows with these diseases were often treated indistinguishably with antibiotics.

Minimum sample size was calculated to allow for an $80 \%$ probability of detecting, at $5 \%$ significance level, the following differences between groups of interest (ClinD21 vs. NoClinD21): $1.0 \mathrm{~kg}$ of milk yield per day $\left(\sigma^{2}=100\right), 250 \mathrm{~kg}$ of milk in $305-\mathrm{d}\left(\sigma^{2}=6 \times 10^{6}\right), 5$ percentage points in pregnancy per breeding (35 vs. $40 \%$ ), $15 \mathrm{~d}$ in average time to pregnancy (130 vs. 145 d), and 10 percentage point in the rate of culling, assuming the ratio of sample size between NoClinD and ClinD would be 3:1. Calculations were performed in the WinPepi program, version 11.65 (Abramson, 2011).

Characterization of Clinical Diseases. Retained placenta was defined as visible fetal membranes at the vulva $24 \mathrm{~h}$ after calving. Metritis was characterized by 
abnormal vaginal discharge observed through the first 21 DIM. Incidence of clinical mastitis was evaluated before every milking and characterized by the presence of abnormal milk or by local signs of inflammation in 1 or more quarters. Cows that stood and walked with arched back and had short strides in 1 or more legs were classified as clinically lame. Digestive problems were characterized by diarrhea, bloat, or displacement of abomasum. Respiratory problems were characterized by increased respiratory frequency associated with fever and presence of increased lung sounds at auscultation. Diagnosis and treatment of clinical diseases were performed by trained personnel and continuously supervised by the herd veterinarians and the University of Florida Food Animal Reproduction and Medicine Service. Treatments were performed according to standard operating procedures of the dairy, which were developed by the herd veterinarians and the University of Florida Food Animal Reproduction and Medicine Service.

Milk Production and Composition. Daily milk yields were summarized weekly and evaluated through wk 14 of lactation. The week with the highest average production was considered the week of peak production. Average weekly production at peak and interval to peak production in weeks also were summarized for each cow, with at least $14 \mathrm{wk}$ of milk production data. In addition, 305-d yields of milk, fat, and protein were measured. Cows that left the herd before 100 DIM did not contribute to the 305-d yield data, and those that left the herd from 100 to 304 DIM contributed with their projected values. The projected values were obtained from the PCDART computer software, based on official DHIA tests, and account for production and DIM at test days, parity, calving season, and region of the farm. Energy-corrected milk (ECM) was calculated by the following equation: $\mathrm{ECM}=[(0.327 \times \mathrm{kg}$ of milk $)+(12.95 \times \mathrm{kg}$ of milk fat $)+(7.20 \times \mathrm{kg}$ of milk protein)]. Finally, data records referent to yields of milk, fat, and protein, and fat and protein percentages assessed after the first 3 official DHIA milk tests were also evaluated.

Reproductive Management. The voluntary waiting period (VWP) of the herd was 55 DIM. Estrus detection and synchronization of the estrous cycle were used concomitantly for breeding of eligible cows by AI or embryo transfer (ET). After the end of the VWP, cows were evaluated daily for signs of estrus, and those observed in estrus were inseminated on the same day or received an embryo 6 to $9 \mathrm{~d}$ later. Cows not observed in estrus were bred after a Presynch-Ovsynch synchronization program $\left[\mathrm{PGF}_{2 \alpha}\right.$ at 56 and 70 DIM, GnRH at 82 DIM, PGF PF $_{2 \alpha}$ at 89 DIM, GnRH at 91 (p.m.) DIM]. Af- ter the first postpartum breeding, cows that returned to estrus were considered nonpregnant and were rebred on the same day. Pregnancy diagnosis of cows that did not return to estrus was performed by transrectal palpation $45 \mathrm{~d}$ after breeding. Cows diagnosed pregnant were rechecked $45 \mathrm{~d}$ later, and those reconfirmed pregnant were followed until termination of pregnancy, either by abortion or by calving. Cows diagnosed nonpregnant at pregnancy diagnoses were enrolled in an Ovsynch program for rebreeding. Date and outcome of all breedings performed through 305 DIM were recorded. Cows that were culled before the end of the VWP and those designated ineligible for breeding due to management decisions ("do not breed" cows) did not contribute to the reproductive performance data. Nonetheless, the proportion of cows designated ineligible for breeding was also evaluated.

Reproductive outcomes included the interval to first postpartum breeding (AI or ET), interval to first pregnancy based on pregnancy diagnosis on d 45 after breeding, and interval to first pregnancy that resulted in a subsequent calving. In addition, pregnancy per breeding, calving per breeding, and late pregnancy losses (after gestational d 45) were evaluated for all breedings according to DIM at breeding, categorized in 4 ranges as follows: 56 to 100,101 to 150,151 to 200 , or 201 to 305 .

Culling. Date of and reason for culling were recorded for all cows that left the herd by 305 DIM. Culling included all cows that died and those that were sold for beef or dairy purposes. Interval to culling and proportion of cows culled by 305 DIM were evaluated. Information regarding culling after 305 DIM was not collected.

Statistical Analyses. Statistical analyses were performed in SAS, version 9.3 (SAS/STAT, SAS Institute Inc., Cary, NC). Continuous variables were analyzed by linear regression and ANOVA and binary variables were analyzed by logistic regression using the GLIMMIX procedure. The interval to an event was analyzed by the Cox's proportional hazard model, using the PHREG procedure of SAS. The median and mean days to an event were obtained from the LIFETEST procedure. Survival plots were generated with MedCalc, version 12.7.2 (MedCalc, Mariakerke, Belgium).

The statistical models included the effects of ClinD21, parity, calving season categorized in trimesters within the year, and their interactions. Orthogonal contrasts of the independent variable ClinD21 were performed to evaluate the effects of incidence of ClinD21 (NoClinD21 vs. single ClinD21 + multiple ClinD21) and number of ClinD21 (single ClinD21 vs. multiple ClinD21). To evaluate the effects of UTD and NUTD, alone or com- 
bined, a second statistical model was used, in which clinical status during the first 21 DIM was categorized as NoClinD21, UTD only, NUTD only, or both UTD and NUTD. Additive effects of UTD and NUTD were evaluated by the contrast of interest that compared UTD only + NUTD only vs. both UTD and NUTD.

Weekly average yields of milk during the first $14 \mathrm{wk}$ postpartum, and milk yield and composition in the first 3 DHIA milk tests were analyzed as repeated measures. In these analyses, week postpartum or test number, and their interaction with ClinD21, parity, and season of calving, were included in the statistical models. Moreover, cow nested within ClinD21 group was included as a random effect. For analyses of pregnancy per breeding, calving per breeding, and pregnancy losses, breeding was the experimental unit, and the statistical models also included the effects of breeding type (AI or ET), breeding number, categorized DIM at breeding, and the interaction between categorized DIM at breeding and ClinD21. Statistical differences were characterized by $P \leq 0.05$.

\section{Study 2}

This retrospective cohort study examined data collected from 2,415 primiparous Holstein cows with genomic testing information that calved between September 2014 and May 2017 in the same herd described in Study 1. The group of cows evaluated in Study 2 is completely different from the group of cows evaluated in Study 1. General management of cows, study design, and collection of 305-d yields of milk, milk fat, and milk protein were identical to Study 1. In addition, genomic EBV (GEBV) for yields of milk, fat, and protein were calculated as $2 \times$ the genomic PTA (GPTA), which in turn was obtained from a commercial genomic test (Clarifide, Zoetis Genetics, Kalamazoo, MI). The predicted 305-d yields of milk, fat, and protein were calculated based on GPTA for milk, fat, and protein, respectively. To calculate the predicted production traits, the average GPTA of all heifers was subtracted from the individual GPTA, and the difference was then summed to the average of observed values for each variable.

Minimum sample size was calculated to allow for an $80 \%$ probability of detecting a $200-\mathrm{kg}$ difference in 305 -d milk yield $\left(\sigma^{2}=6 \times 10^{6}\right)$ and a $60-\mathrm{kg}$ difference in GEBV for milk $\left(\sigma^{2}=2 \times 10^{5}\right)$ between groups of interest (NoClinD21 vs. ClinD21) at 5\% significance level, assuming that the ratio of sample size between groups would be 3:1. Genomic EBV, predicted 305-d yields, observed 305-d yields, and the difference between predicted and observed 305-d yields were ana- lyzed by ANOVA using the GLIMMIX procedure of SAS. Statistical models for GEBV and predicted 305-d yields included the effects of ClinD21 only. Statistical models for observed 305-d yields and for the differences between observed and predicted 305-d yields included the effects of ClinD21, calving season categorized in trimesters within a year, year of calving, and age at calving (in days: $<688,688$ to 730 , or $>730$ ). Statistical differences were characterized by $P \leq 0.05$.

\section{RESULTS}

\section{Study 1}

Incidence of Diseases. From calving through 305 DIM, 2,335 cows (45.9\%) had at least one clinical disease (Figure 1$)$. The mean $( \pm \mathrm{SD})$ and median time to the first postpartum clinical disease were $48.2( \pm 66.1)$ and $15 \mathrm{~d}$, respectively. The overall incidences of UTD and NUTD were $21.6 \%$ and $31.7 \%$, respectively. Of NUTD, incidence of individual diseases was mastitis $15.3 \%$, lameness $10.5 \%$, digestive problem $9.3 \%$, and respiratory problem $2.0 \%$. The total number of clinical cases diagnosed through 305 DIM was 3,277.

During the first 21 DIM, 1,534 cows $(30.2 \%)$ had at least one clinical disease (Figure 1). These cows represented $65.7 \%$ of all cows diagnosed with at least 1 clinical disease through 305 DIM. The incidences of UTD and NUTD during the first 21 DIM were $21.6 \%$ and $12.4 \%$, respectively. Of the NUTD, the incidence of individual diseases was mastitis $5.7 \%$, lameness $1.5 \%$, digestive problem $5.5 \%$, and respiratory problem $0.6 \%$. The total number of clinical cases during the first 21 DIM was 1,771 , which represents $55.1 \%$ of all clinical cases diagnosed through 305 DIM. Of all cows, 1,309 $(25.7 \%)$ had a single ClinD21, and 225 (4.4\%) had multiple ClinD21. In addition, $906(17.8 \%)$ had only UTD, $438(8.6 \%)$ had only NUTD, and $190(3.7 \%)$ had both UTD and NUTD. Clinical disease during the first 21 DIM was not associated with the proportion of cows with disease after 21 DIM (NoClinD21 $=23.0 \%$, vs. ClinD21 $=24.5 \% ; P=0.18$ ), although the rate of incidence was higher in cows with ClinD21 compared with those without ClinD21 [adjusted hazard ratio (AHR) $=1.20 ;$ CI 1.07 to $1.37 ; P<0.01]$.

Milk Yield and Components. Clinical disease during the first 21 DIM decreased the 305-d yields of milk $(10,043 \mathrm{~kg}$ vs. $10,453 \mathrm{~kg} ; P<0.01)$, fat $(361 \mathrm{~kg}$ vs. $378 \mathrm{~kg} ; P<0.01$ ), protein $(291 \mathrm{~kg}$ vs. $303 \mathrm{~kg} ; P<$ $0.01)$, and ECM $(10,054 \mathrm{~kg}$ vs. $10,499 \mathrm{~kg} ; P<0.01)$. Yields of milk and fat were also associated $(P<0.01)$ with the number of ClinD21 (Table 1). Uterine disease alone and NUTD alone caused similar reductions $(P$ 
$\%$ of all cows Cumulative $\%$

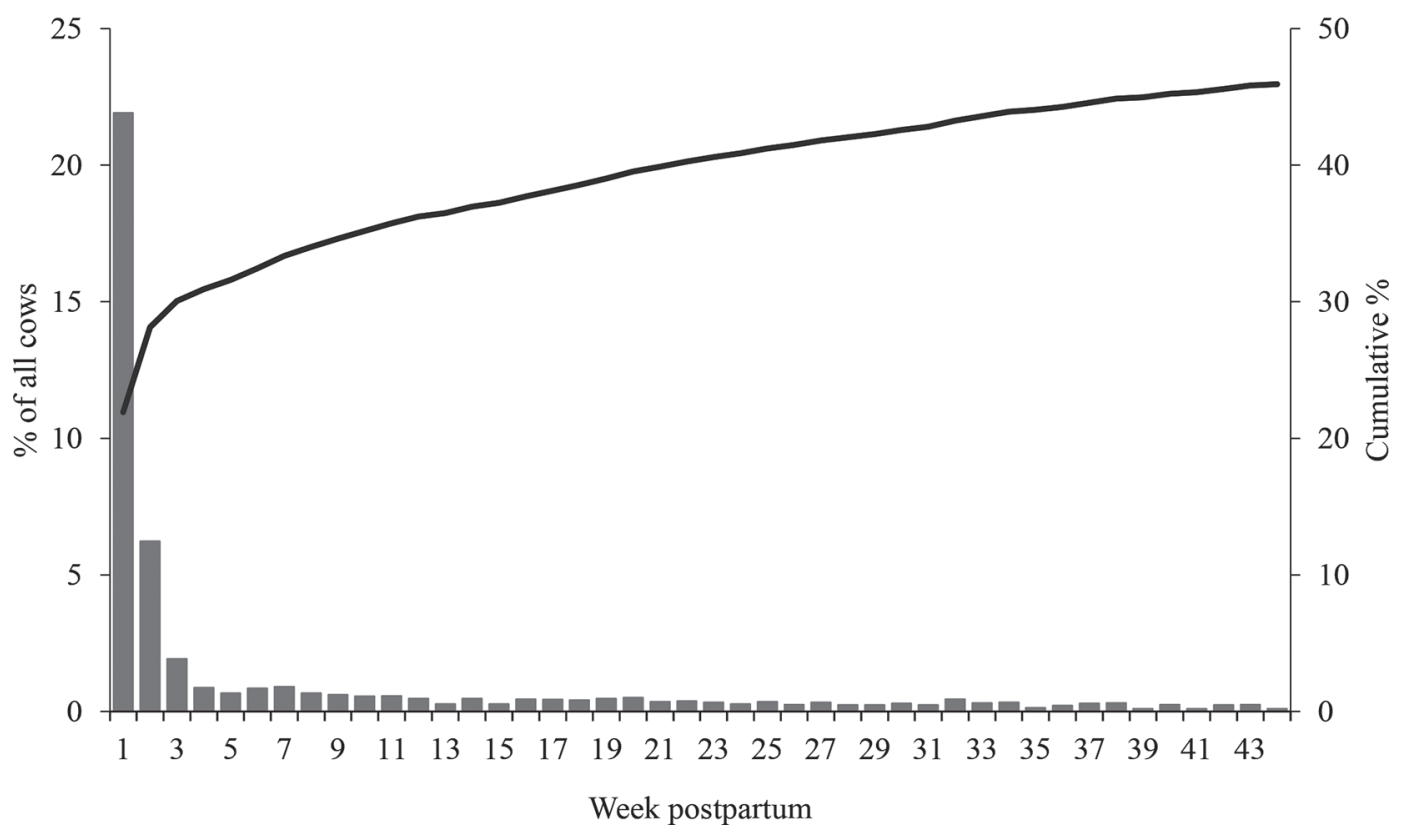

Figure 1. Weekly and cumulative percentages of cows diagnosed with first postpartum clinical disease by week postpartum. The number of cows evaluated was 5,085 .

$<0.01)$ on yields of milk, fat, and protein, and had additive negative effects $(P<0.05)$ on yields of milk, protein, and ECM. The adjusted means of 305-d yields were $10,453,10,100,10,094$, and $9,727 \mathrm{~kg}$ of milk; 378.5 , $363.9,359.7$, and $350.6 \mathrm{~kg}$ of fat; 302.7, 293.2, 291.4, and $281.9 \mathrm{~kg}$ of protein; and 10,499, 10,124, 10,059, and $9,751 \mathrm{~kg}$ of ECM for NoClinD21, UTD only, NUTD only, and both UTD and NUTD, respectively.

The first 3 official milk tests were performed at similar postpartum intervals for cows with or without ClinD21, averaging 30, 60, and 90 DIM, respectively (Table 1). Yields of milk, fat, and protein, and percentage of protein in the first 3 official milk tests, were associated $(P<0.05)$ with incidence and number of ClinD21 (Table 1). Percentage of fat, however, was not associated with incidence or number of ClinD21 (Table 1). In addition, UTD alone and NUTD alone had similar negative effects $(P<0.01)$ and additive effects $(P$ $<0.05$ ) on yields of milk, protein, and fat in the first 3 official tests. Milk protein percentage was increased similarly by UTD alone and NUTD alone, but an additive effect of the 2 types of diseases was not observed. Milk fat percentage was not associated with UTD and NUTD, alone or combined.

Daily milk yield during the first 14 wk in milk, summarized weekly, was associated with incidence (NoClinD21 $=38.4 \mathrm{~kg}$, vs. ClinD21 $=35.4 \mathrm{~kg} ; P<0.01)$ and number of ClinD21 (none $=38.4 \mathrm{~kg}$, vs. single $=35.8 \mathrm{~kg}$, vs. multiple $=33.4 \mathrm{~kg} ; P<0.01$; Figure $2 \mathrm{~A})$. An interaction between ClinD21 and time was also observed $(P<0.01)$ because the estimated differences increased from wk 1 to 2 and then decreased from wk 2 to 14 . Within a week, the estimated differences between NoClinD21 and ClinD21 were 2.9, 5.8, 5.3, 4.9, 4.2, 3.6, $3.0,2.5,2.1,1.8,1.6,1.3,1.3$, and $1.1 \mathrm{~kg}$ from wk 1 to 14 , respectively, which were all different $(P<0.03)$. In addition to overall milk production, milk yield at peak production (Figure 2B) and interval from parturition to peak milk production (Figure $2 \mathrm{C}$ ) also were associated $(P<0.01)$ with incidence and number of ClinD21. Cows with ClinD21 had reduced milk yield at peak production $(\mathrm{NoClinD} 21=43.2 \mathrm{~kg}$, vs. $\mathrm{ClinD} 21=41.3$ $\mathrm{kg} ; P<0.01)$ and extended interval from parturition to peak production $(\mathrm{NoClinD} 21=7.4 \mathrm{wk}$, vs. ClinD21 $=$ 8.6 wk; $P<0.01)$.

The effect of ClinD21 on milk production during the first 14 wk in milk also interacted with parity $(P<$ 0.01 ), because in general estimated differences were larger in multiparous than in primiparous cows (Figure 3A). Similarly, an interaction $(P<0.01)$ between ClinD21 and parity was also observed for peak milk yield (Figure 3B) and interval from parturition to peak milk production (Figure $3 \mathrm{C}$ ), as the estimated differences were larger in multiparous cows $(2.6 \mathrm{~kg}$ and 1.4 
Table 1. Effects of clinical disease during the first 21 DIM (ClinD21) on milk production and milk components resulting from the first 3 postpartum official DHIA tests and 305-d yields of milk, fat, and protein ${ }^{1}$

\begin{tabular}{|c|c|c|c|c|c|c|}
\hline \multirow[b]{2}{*}{ Item } & \multicolumn{3}{|c|}{ Number of ClinD21 ${ }^{2}$} & \multirow[b]{2}{*}{$P$-value } & \multicolumn{2}{|c|}{ Contrast $^{3}$} \\
\hline & None & Single & Multiple & & $\mathrm{C} 1$ & $\mathrm{C} 2$ \\
\hline First test & $29.9 \pm 0.16$ & $29.5 \pm 0.27$ & $29.5 \pm 0.76$ & & & \\
\hline Second test & $60.1 \pm 0.17$ & $59.8 \pm 0.28$ & $59.3 \pm 0.78$ & & & \\
\hline Third test & $90.4 \pm 0.17$ & $90.0 \pm 0.28$ & $88.8 \pm 0.79$ & & & \\
\hline Milk yield, kg & & & & $<0.01$ & $<0.01$ & $<0.01$ \\
\hline Third test & $39.1 \pm 0.10^{\mathrm{a}}$ & $38.0 \pm 0.16^{\mathrm{b}}$ & $36.8 \pm 0.46^{\mathrm{c}}$ & & & \\
\hline Fat, $\%$ & & & & 0.96 & 0.92 & 0.91 \\
\hline First test & $3.77 \pm 0.014$ & $3.79 \pm 0.025$ & $3.75 \pm 0.077$ & & & \\
\hline Second test & $3.49 \pm 0.012$ & $3.46 \pm 0.020$ & $3.52 \pm 0.058$ & & & \\
\hline Third test & $3.45 \pm 0.011$ & $3.45 \pm 0.018$ & $3.45 \pm 0.055$ & & & \\
\hline Fat, $\mathrm{kg}$ & & & & $<0.01$ & $<0.01$ & 0.03 \\
\hline First test & $1.48 \pm 0.006^{\mathrm{a}}$ & $1.37 \pm 0.011^{\mathrm{b}}$ & $1.27 \pm 0.035^{\mathrm{c}}$ & & & \\
\hline Third test & $2.73 \pm 0.004^{\mathrm{b}}$ & $2.75 \pm 0.006^{\mathrm{a}}$ & $2.78 \pm 0.019^{\mathrm{a}}$ & & & \\
\hline Protein, $\mathrm{kg}$ & & & & $<0.01$ & $<0.01$ & $<0.01$ \\
\hline First test & $1.08 \pm 0.003^{\mathrm{a}}$ & $1.00 \pm 0.005^{\mathrm{b}}$ & $0.95 \pm 0.017^{\mathrm{c}}$ & & & \\
\hline Second test & $1.09 \pm 0.003^{\mathrm{a}}$ & $1.05 \pm 0.004^{\mathrm{b}}$ & $1.02 \pm 0.013^{\mathrm{c}}$ & & & \\
\hline Third test & $1.06 \pm 0.002^{\mathrm{a}}$ & $1.04 \pm 0.004^{\mathrm{b}}$ & $1.04 \pm 0.012^{\mathrm{b}}$ & & & \\
\hline $305-\mathrm{d}$ yield,${ }^{4} \mathrm{~kg}$ & & & & & & \\
\hline Milk & $10,453 \pm 27.3^{\mathrm{a}}$ & $10,096 \pm 46.0^{\mathrm{b}}$ & $9,750 \pm 135.8^{\mathrm{c}}$ & $<0.01$ & $<0.01$ & 0.02 \\
\hline Fat & $379 \pm 1.54^{\mathrm{a}}$ & $363 \pm 2.59^{\mathrm{b}}$ & $352 \pm 7.65^{\mathrm{b}}$ & $<0.01$ & $<0.01$ & 0.17 \\
\hline Protein & $303 \pm 0.73^{\mathrm{a}}$ & $293 \pm 1.23^{\mathrm{b}}$ & $284 \pm 3.64^{\mathrm{c}}$ & $<0.01$ & $<0.01$ & 0.02 \\
\hline $\mathrm{ECM}$ & $10,499 \pm 29.6^{\mathrm{a}}$ & $10,104 \pm 49.9^{\mathrm{b}}$ & $9,783 \pm 147.3^{\mathrm{c}}$ & $<0.01$ & $<0.01$ & 0.04 \\
\hline
\end{tabular}

${ }^{\mathrm{a}-\mathrm{c}}$ Within a row, column means with different superscript letters differ $(P \leq 0.05)$.

${ }^{1} 4,880$ cows contributed for the data of official milk tests, and 4,655 cows contributed for the data of 305-d yields.

${ }^{2} \mathrm{ClinD} 21$ = clinical disease diagnosed during the first 21 DIM, which included retained placenta, metritis, mastitis, lameness, digestive problems, and respiratory problems. Values given as adjusted means \pm SEM.

${ }^{3} \mathrm{C} 1=$ effect of disease (none vs. single + multiple); $\mathrm{C} 2=$ effect of the number of diseases (single vs. multiple).

${ }^{4} 305$-d yield = actual 305-d yields for cows that remained in the herd for $305 \mathrm{~d}$, and projected yields for cows whose lactation lasted from 100 to $304 \mathrm{~d}$. Cows whose lactation was shorter than $100 \mathrm{~d}$ were not included in the analyses of 305-d yields. Energy corrected milk (ECM) was calculated by the following equation: $\mathrm{ECM}=[(0.327 \times \mathrm{kg}$ of milk $)+(12.95 \times \mathrm{kg}$ of milk fat $)+(7.20 \times \mathrm{kg}$ of milk protein $)]$.

wk, respectively) than in primiparous cows $(1.3 \mathrm{~kg}$ and $0.9 \mathrm{wk}$, respectively).

Reproductive Outcomes. Of all cows enrolled in the study, 752 cows were not enrolled in the breeding program either because of culling before the end of VWP $(n=264)$ or because of management decision $(\mathrm{n}=488)$. The proportion of cows not enrolled in the breeding program was associated with incidence and number of ClinD21 (Table 2), and it was greater for cows diagnosed with ClinD21 (NoClinD21 $=11.4 \%$, vs. ClinD21 $=22.8 \% ; P<0.01)$. We also found an interaction $(P<0.01)$ between ClinD21 and parity, as the estimated differences between groups were larger in multiparous (NoClinD21 $=14.7 \%$, vs. ClinD21 $=$ $30.6 \% ; P<0.01)$ than in primiparous cows $($ NoClinD21 $=5.4 \%$, vs. ClinD21 $=8.6 \% ; P<0.01)$.

Among cows that survived to the end of VWP and were eligible to be bred $(\mathrm{n}=4,333)$ either by AI or $\mathrm{ET}$,
$98.3 \%$ were bred at least once. On average, the $1.7 \%$ of cows that were not bred stayed in the herd for only $18 \mathrm{~d}$ after the end of VWP. The proportion of cows bred was associated with ClinD21 (Table 2), and it was smaller for cows diagnosed with ClinD21 (NoClinD21 $=98.6 \%$, vs. ClinD21 $=97.2 \% ; P<0.01)$. For cows that were bred, however, the interval from parturition to first postpartum breeding was not associated with ClinD21 and averaged $81 \mathrm{~d}$ (Table 2; Figure 4A). Similarly, UTD and NUTD were not associated with time to first breeding, neither alone nor combined.

Of all eligible cows $(\mathrm{n}=4,333), 3,747$ cows $(86.5 \%)$ were diagnosed pregnant $45 \mathrm{~d}$ after breeding, and this proportion was associated $(P<0.01)$ with incidence and number of ClinD21 (Table 2). The proportion of cows diagnosed pregnant was lower in cows with ClinD21 (NoClinD21 $=88.4 \%$, vs. ClinD21 $=81.4 \%$; $P<0.01)$. Pregnancy rate and the interval from calv- 

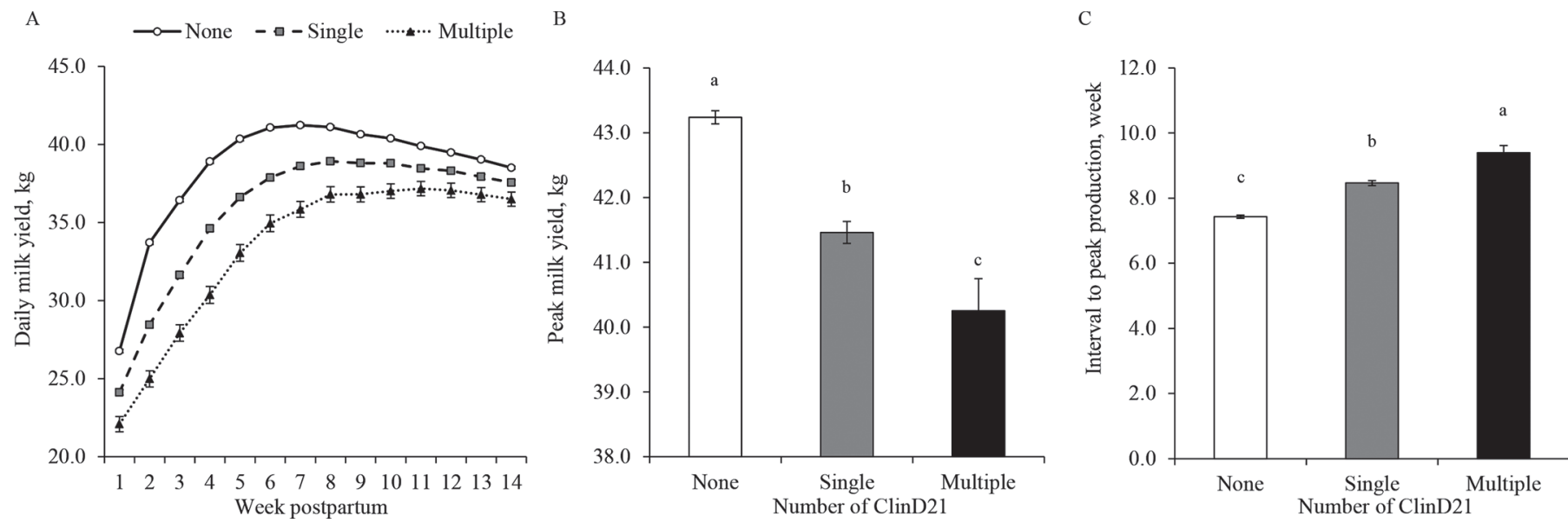

Figure 2. Effect of the number of clinical disease during the first 21 DIM (ClinD21; none, single, or multiple) on average daily milk yield (A), peak milk yield (B), and interval from parturition to peak milk production (C). Clinical diseases include metritis, mastitis, lameness, digestive problems, and respiratory problems. Error bars represent SEM in all panels. In panel A, all pairwise comparisons within a week were different $(P<0.03)$. In panels $\mathrm{B}$ and $\mathrm{C}$, lowercase letters a-c represent differences $(P<0.01)$ between groups of interest. The number of cows that contributed data was 4,918 in panel $\mathrm{A}$ and 4,635 in panels $\mathrm{B}$ and $\mathrm{C}$.

ing to pregnancy were also associated $(P<0.01)$ with ClinD21 (Table 2; Figure 4B). The AHR for pregnancy was lower in cows diagnosed with ClinD21 (NoClinD21 $=1.0$, vs. ClinD21 $=0.81[0.76-0.88] ; P<0.01)$. When data were analyzed according to the type of disease, UTD alone, but not NUTD alone, had a negative effect on the proportion of cows diagnosed pregnant, and a negative additive effect of the 2 types of disease was also observed (NoClinD21 $=88.4 \%$, vs. UTD only $=$ $80.8 \%$, vs. NUTD only $=86.1 \%$, vs. both UTD and NUTD $=73.4 \% ; P<0.01)$. Similarly, pregnancy rate was associated with UTD alone $[\mathrm{AHR}=0.78(0.71$ to $0.85) ; P<0.01]$ but not with NUTD alone $[$ AHR $=$ 0.96 (0.84 to 1.09); $P=0.54$ ], and the 2 diseases combined had the worst pregnancy rate $[\mathrm{AHR}=0.74(0.60$ to 0.91$) ; P<0.01]$ compared with the reference group NoClinD21.

Of all eligible cows $(\mathrm{n}=4,333), 2,981(68.8 \%)$ had a new calving, and this proportion was influenced $(P$ $<0.01$ ) by incidence and number of ClinD21 (Table 2 ; Figure $4 \mathrm{C})$. The proportion of cows that calved again was lower in cows with ClinD21 (NoClinD21 $=72.8 \%$,
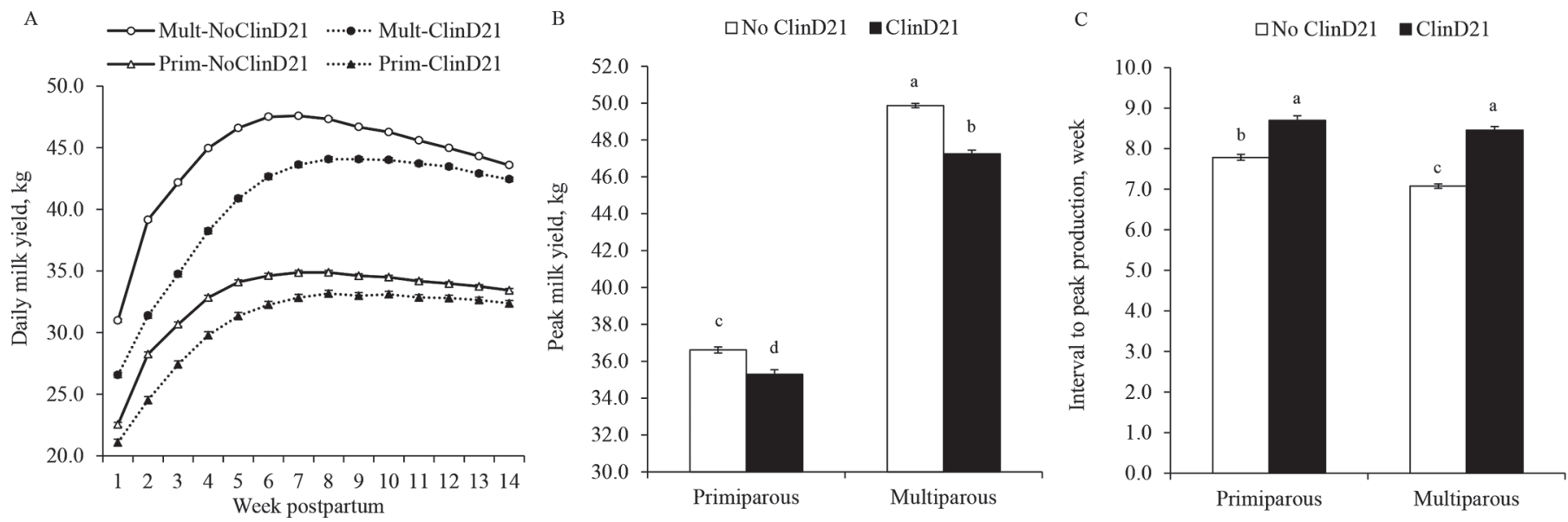

Figure 3. Effect of clinical disease during the first 21 DIM (ClinD21 or NoClinD21) and parity (Mult = multiparous; Prim = primiparous) on average daily milk yield (A), peak milk yield (B), and interval from parturition to peak milk production (C). Clinical diseases include metritis, mastitis, lameness, digestive problems, and respiratory problems. Error bars represent SEM in all panels. In panel A, all pairwise comparisons within a week were different $(P<0.01)$. In panels $\mathrm{B}$ and $\mathrm{C}$, lowercase letters a-d represent differences $(P<0.01)$ between groups of interest. The number of cows that contributed data was 4,918 in panel A and 4,635 in panels B and $\mathrm{C}$. 


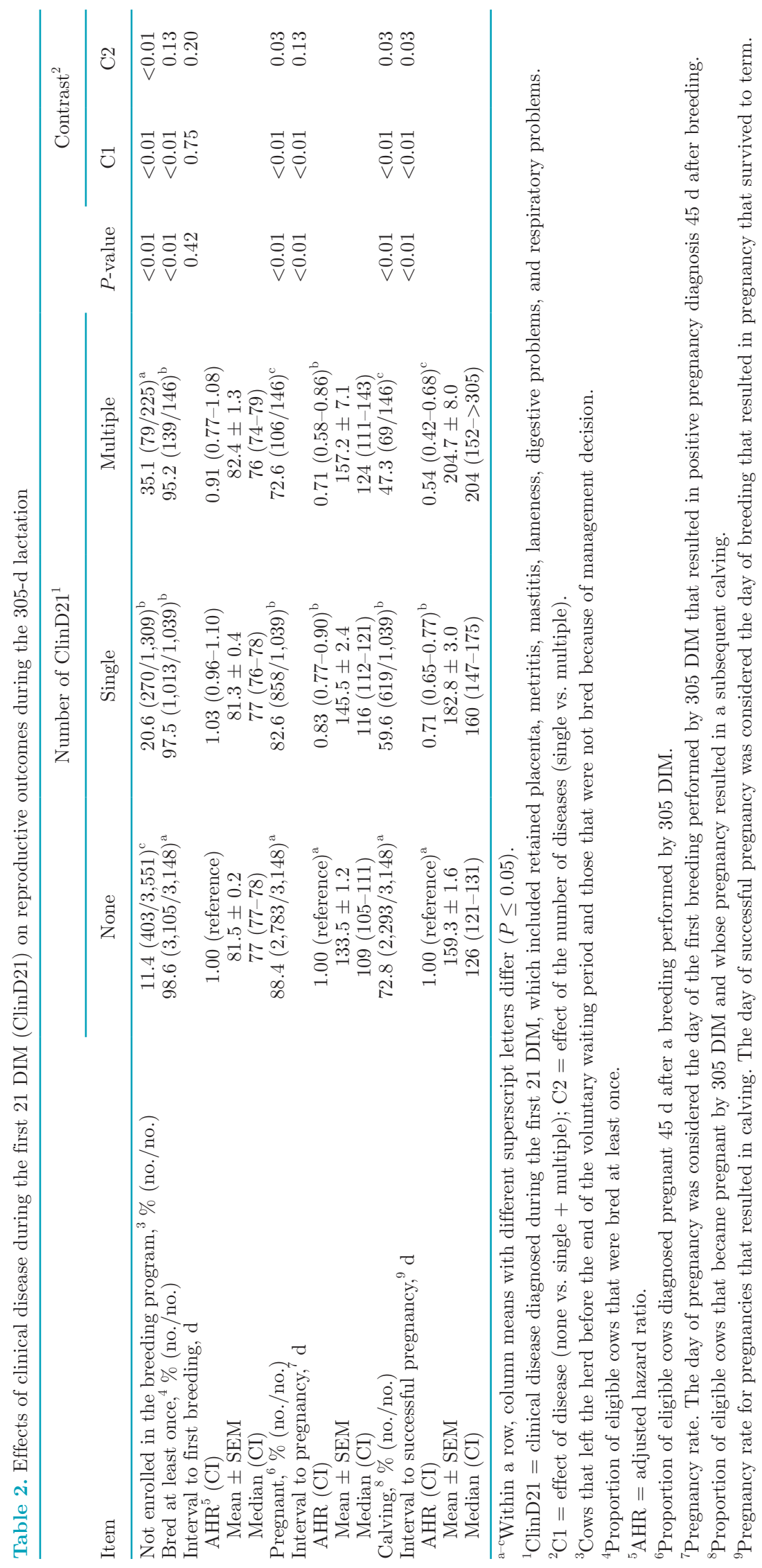



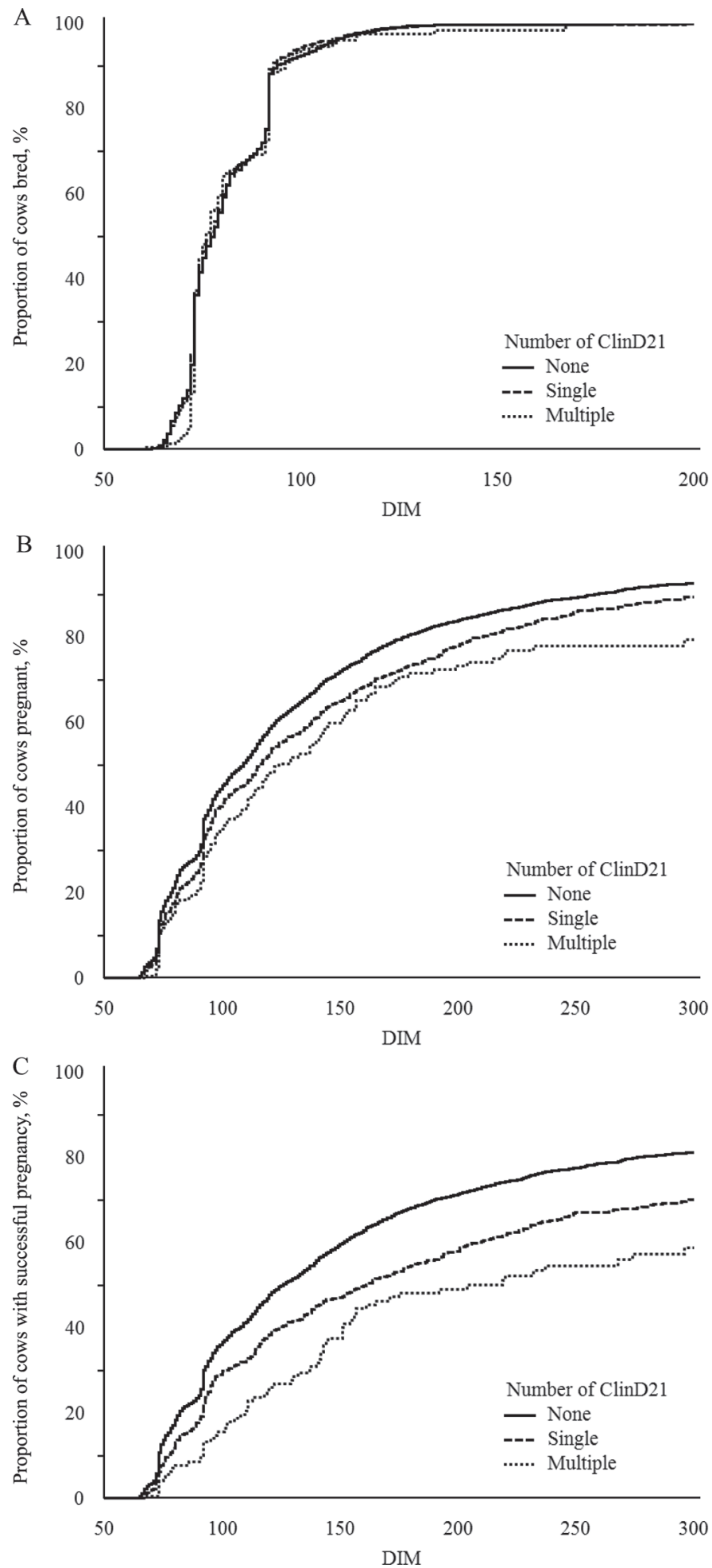

Figure 4. Survival probabilities for breeding (A), pregnancy based on pregnancy diagnosis on d 45 (B), and pregnancy that resulted in a subsequent calving $(\mathrm{C})$ according to incidence of clinical disease during the first 21 DIM (ClinD21; none, single, or multiple) and DIM. In panels B and C, the day of pregnancy was considered the day of breeding that resulted in the respective pregnancy. The number of cows that contributed data was 4,333 . vs. ClinD21 $=58.1 \% ; P<0.01)$. The rate of pregnancy that resulted in a new calving was also affected $(P<$ 0.01 ) by incidence and number of ClinD21 (Table 2). The AHR for successful pregnancy (resulting in calving) was lower in cows diagnosed with ClinD21 [NoClinD21 $=1.0$, vs. ClinD21 $=0.69$ (0.63 to 0.75); $P<$ 0.01]. When data were analyzed according to the type of disease, both UTD alone and NUTD alone had negative effects on the proportion of cows that calved again, and a negative additive effect of the 2 types of diseases was also observed $(\mathrm{NoClinD} 21=72.8 \%$, vs. UTD only $=56.6 \%$, vs. NUTD only $=66.3 \%$, vs. both UTD and NUTD $=47.6 \% ; P<0.01)$. The rate of pregnancy that resulted in a new calving was decreased by UTD alone $[\mathrm{AHR}=0.64(0.58$ to 0.71$) ; P<0.01]$ and by UTD and NUTD combined $[$ AHR $=0.55$ (0.42 to 0.71$) ; P<$ 0.01 , but not by NUTD alone $[\mathrm{AHR}=0.88(0.76$ to 1.01); $P=0.08$.

Pregnancy per breeding, for all breedings performed through 305 DIM, was not associated with ClinD21 $($ NoClinD21 $=30.7 \%$, vs. ClinD21 $=27.0 \% ; P=0.08$; Figure 5A). Nonetheless, in terms of range of DIM category, cows diagnosed with ClinD21 had reduced pregnancy per breeding $(P<0.05)$ in ranges 1 (56 to 100 DIM) and 2 (101 to 150 DIM), but not in ranges 3 (151 to $200 \mathrm{DIM}$ ) and 4 (>200 DIM; Figure 5A). Number of diseases was not associated with pregnancy per breeding, as it was similar for cows with single or multiple diseases $($ single $=27.1 \%$, vs. multiple $=26.9 \% ; P=$ $0.60)$. When data were analyzed according to the type of disease, UTD and NUTD were not associated with pregnancy per breeding, neither alone nor combined.

Calving per breeding for all breedings performed through 305 DIM was lower $(P<0.01)$ in cows with ClinD21 $($ NoClinD21 $=24.6 \%$, vs. ClinD21 $=18.5 \%$; Figure 5B). Within range of DIM category, calving per breeding was lower $(P<0.05)$ in cows diagnosed with ClinD21 in ranges 1 (56 to 100 DIM), 2 (101 to 150 DIM), and 3 (151 to 200 DIM), but not in range 4 (>200 DIM; Figure 5B). Number of diseases was not associated with calving per breeding, as it was similar for cows with single or multiple diseases (single $=$ 18.8 , vs. multiple $=16.0 \% ; P=0.54$ ). When data were analyzed according to the type of disease, UTD alone or combined with NUTD, but not NUTD alone, was associated with lower rate of calving per breeding (NoClinD21 $=24.6 \%$, vs. UTD only $=17.4 \%$, vs. NUTD only $=22.2 \%$, vs. both UTD and NUTD $=17.1 \% ; P$ $<0.01)$.

Pregnancy loss after gestational d 45 for all breedings performed through 305 DIM was greater $(P<0.01)$ in cows with ClinD21 (NoClinD21 $=13.9 \%$, vs. ClinD21 $=23.6 \%$ ) and this response was consistent across all 

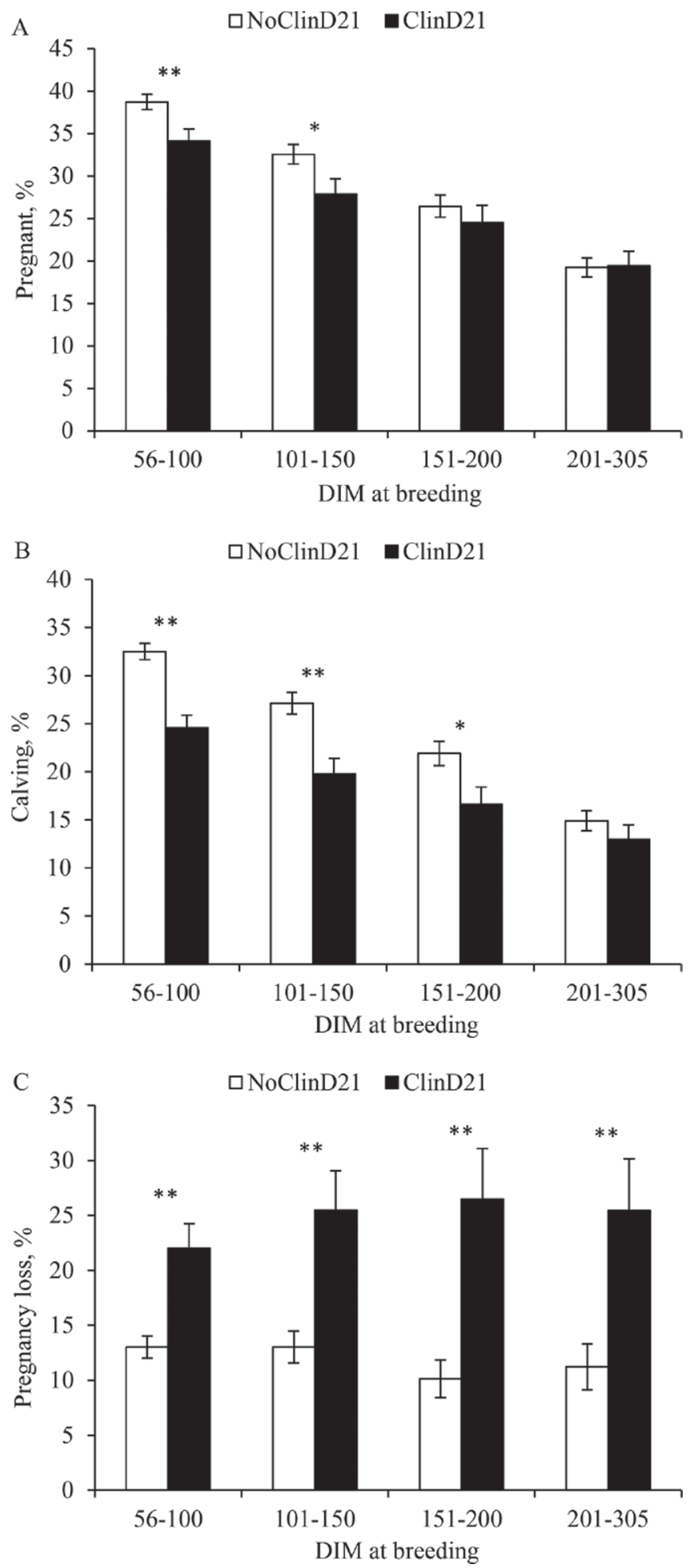

Figure 5. Pregnancy per breeding (A), calving per breeding (B), and pregnancy loss after gestational d $45(\mathrm{C})$ according to incidence of clinical disease during the first 21 DIM (ClinD21 or NoClinD21) and DIM when breeding was performed. In all panels, error bars represent SEM, and differences between groups of interest within a range of DIM category are represented by $*(P<0.05)$ and $* *(P<0.01)$. Panel A includes data of 13,446 breedings, panel $\mathrm{B}$ includes data of 13,022 breedings, and panel $\mathrm{C}$ includes data of 3,564 pregnancies. categorized DIM ranges (Figure 5C). Number of diseases was not associated with pregnancy losses, as it was similar for cows with single or multiple diseases (single $=22.4 \%$, vs. multiple $=32.4 \% ; P=0.75$ ). When data were analyzed according to type of disease, UTD alone and NUTD alone affected pregnancy losses (NoClinD21 $=13.9 \%$, vs. UTD only $=24.7 \%$, vs. NUTD only $=$ $16.7 \%$, vs. both UTD and NUTD $=34.4 \% ; P<0.01$ ).

Culling. Of all cows enrolled, 1,391 (27.4\%) left the herd before completing 305 DIM. Both the proportion of cows culled and the rate of culling were influenced by incidence and number of ClinD21 (Table 3; Figure 6A). A greater proportion of cows with ClinD21 left the herd compared with those without ClinD21 (NoClinD21 = $22.6 \%$, vs. ClinD21 $=38.3 \% ; P<0.01$ ), and the rate of culling was also increased $[\mathrm{AHR}=1.95$ (1.76 to 2.17); $P<0.01]$. Both UTD alone and NUTD alone increased culling, and the 2 combined had an additive effect (NoClinD21 $=22.6 \%$, vs. UTD only $=31.8 \%$, vs. NUTD only $=45.2 \%$, vs. both UTD and NUTD $=53.7 \% ; P$ $<0.01)$. The rate of culling was affected by both UTD alone $[$ AHR $=1.53$ (1.34 to 1.75); $P<0.01$ ] and NUTD alone $[\mathrm{AHR}=2.49$ (2.13 to 2.91$) ; P<0.01]$, and the 2 types of disease had an additive effect $[$ AHR $=3.03$ (2.46 to 3.72$) ; P<0.01]$. When cows that left the herd by 21 DIM were excluded from the analyses, all the reported associations of incidence, number, and type of ClinD21 with proportion of cows culled and with the rate of culling were still present (Table 3).

Of all cows that were culled, $267(5.3 \%)$ died, and $1,124(22.1 \%)$ were sold for either beef $(n=1,008)$ or dairy $(\mathrm{n}=116)$ purposes. The proportion of cows sold and the rate of sale were both increased by incidence and number of ClinD21 (Table 3). Both UTD alone and NUTD alone increased the proportion of cows sold (NoClinD21 $=19.1 \%$, vs. UTD only $=25.6 \%$, vs. NUTD only $=32.9 \%$, vs. both UTD and NUTD $=36.8 \% ; P<$ $0.01)$. Similarly, the rate of sale was increased by both UTD alone $[\mathrm{AHR}=1.45$ (1.25 to 1.68$) ; P<0.01]$ and NUTD alone $[$ AHR $=2.23$ (1.87 to 2.68); $P<0.01$ ], and the 2 types of disease combined had an additive effect $[$ AHR $=2.58(2.01$ to 3.30$) ; P<0.01]$. When cows that left the herd by 21 DIM were excluded from the analyses, all the reported associations of incidence, number, and type of disease with the proportion of cows sold and on the rate of sale were still present (Table 3).

Incidence and number of ClinD21 were also associated with the rate of mortality during the 305-d period (Table 3), and mortality rate was greater for cows with ClinD21 $[\mathrm{AHR}=2.91(2.29$ to 3.71$) ; P<0.01]$. The proportion of cows that died, however, was associated with incidence $($ NoClinD21 $=3.5$, vs. ClinD21 $=9.3 \%$; $P<0.01$ ) but not with the number (single $=8.1 \%$, vs. multiple $=16.0 \%$ ) of ClinD21 (Table 3). Both UTD 
EFFECT OF POSTPARTUM DISEASE ON PERFORMANCE

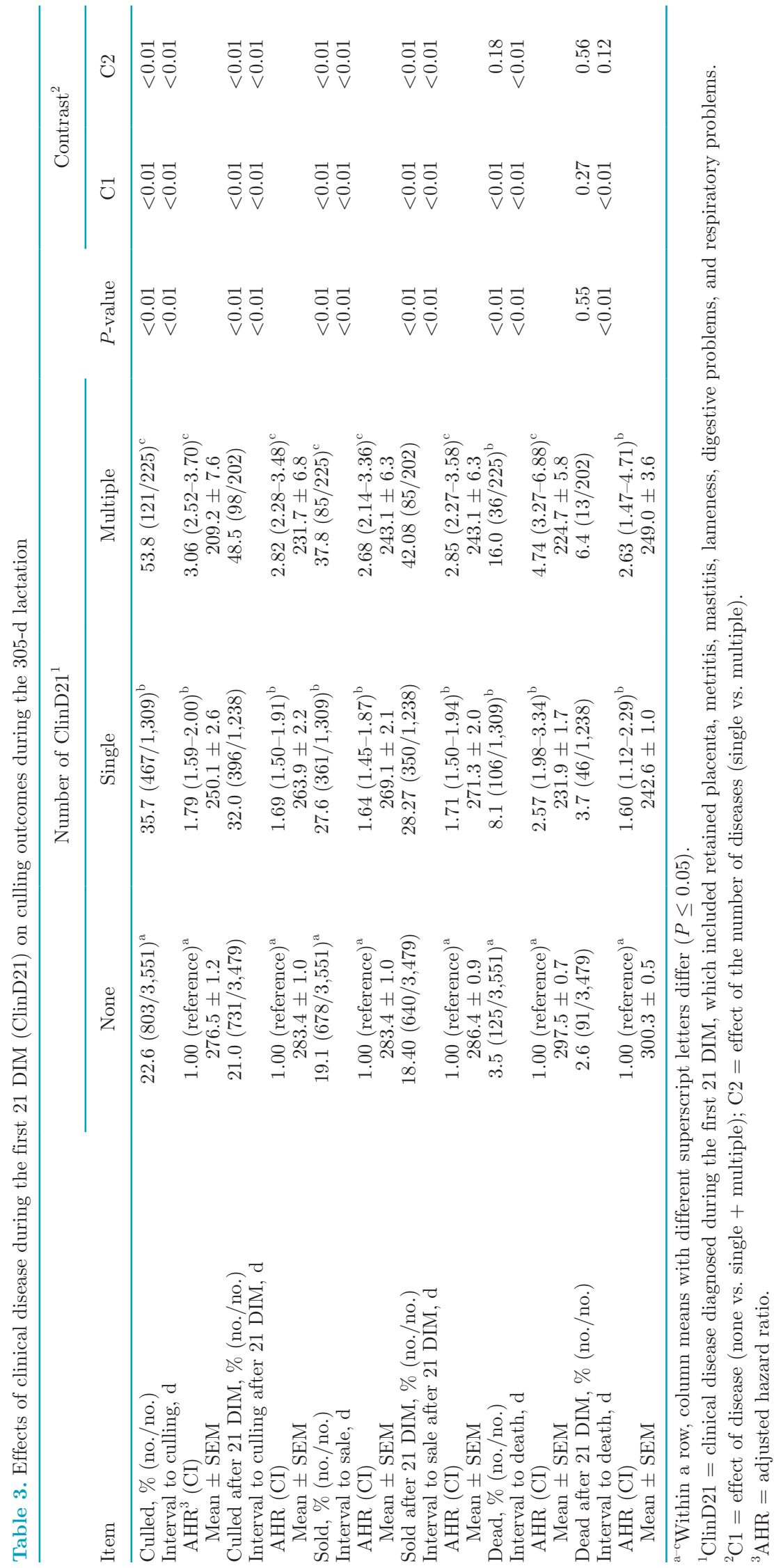



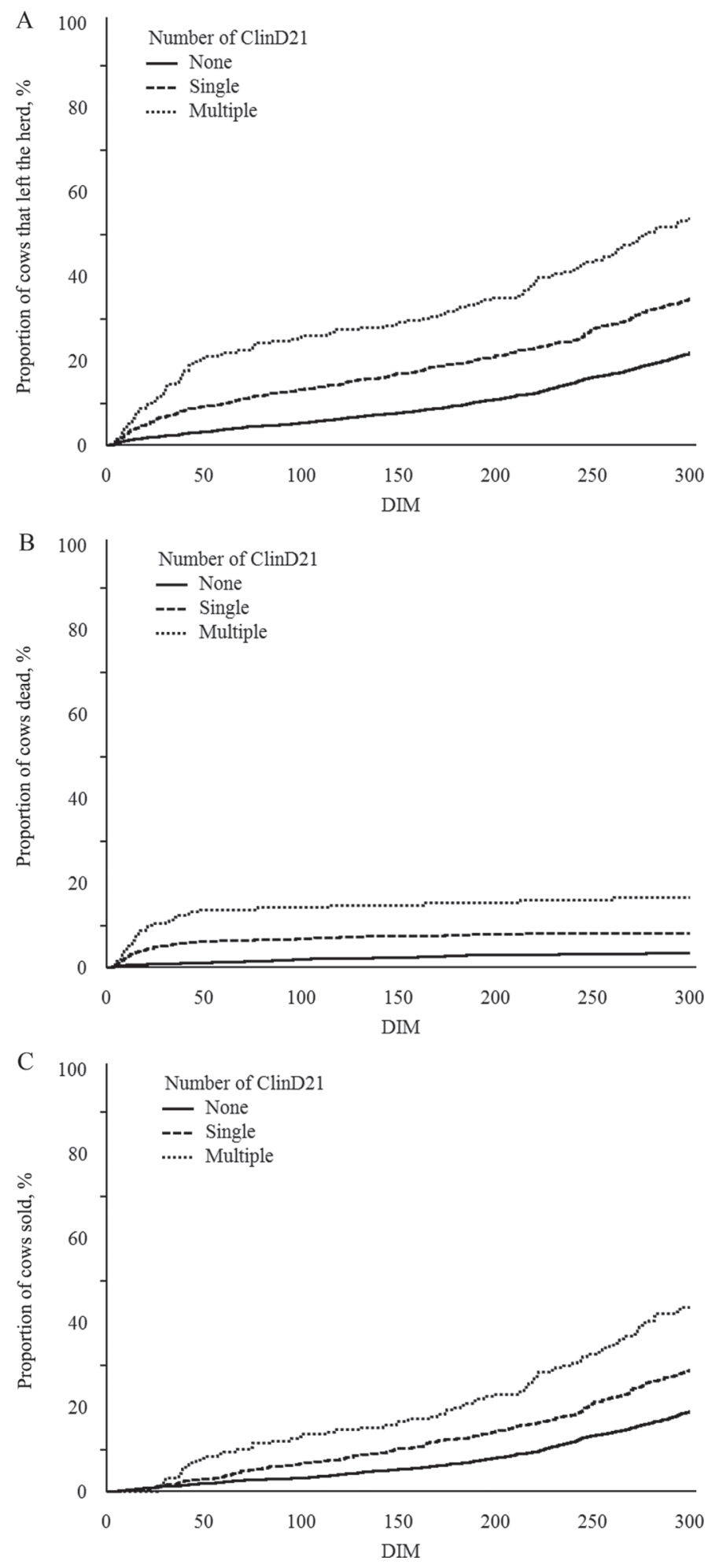

Figure 6. Survival probabilities of culling (A), mortality (B), and sale (C) according to incidence of clinical disease during the first 21 DIM (ClinD21; none, single, or multiple) and DIM. The number of cows that contributed data was 5,085 . alone and NUTD alone increased the proportion of cows that died $($ NoClinD21 $=3.5 \%$, vs. UTD only $=6.2 \%$, vs. NUTD only $=12.3 \%$, vs. both UTD and NUTD = $16.8 \% ; P<0.01)$. Similarly, the rate of mortality was increased by both UTD alone $[\mathrm{AHR}=2.00$ (1.46 to 2.75); $P<0.01]$ and NUTD alone $[$ AHR $=3.69(2.68$ to 5.08); $P<0.01]$, and the 2 types of disease combined had an additive effect $[$ AHR $=5.05$ (3.42 to 7.46$) ; P<$ $0.01]$. When cows that died by 21 DIM were excluded from the analyses, the proportion of cows that died by 305 DIM was not affected by incidence, number, or type of disease (Table 3). The rate of mortality, however, was still associated with incidence of ClinD21 and was greater for cows with ClinD21 $[\mathrm{AHR}=1.75(1.26$ to 2.44); $P<0.01]$. Moreover, the rate of mortality increased in correlation with NUTD alone $[$ AHR $=2.43$ (1.55 to 3.81); $P<0.01$ ] and with NUTD and UTD combined $[\mathrm{AHR}=2.64$ (1.41 to 4.95$) ; P<0.01]$, but not with UTD alone $[\mathrm{AHR}=1.22$ (0.77 to 1.92$) ; P=$ 0.39].

\section{Study 2}

The incidence of ClinD21 in Study 2 was $23.3 \%$ ( 563 out of 2,415). We found no differences in GEBV and predicted 305-d yields of milk, fat, and protein between cows with or without ClinD21 (Table 4). However, the observed 305-d yields of milk, fat, and protein were lower $(P<0.01)$ for cows with ClinD21 compared with cows without ClinD21 (Table 4). Moreover, the differences between observed and predicted 305-d yields for milk, fat, and protein were greater $(P<0.01)$ for cows with ClinD21 compared with cows without ClinD21 (Table 4).

\section{DISCUSSION}

We evaluated the long-term consequences of clinical disease that occur during the early postpartum period on milk production, reproduction, and culling of dairy cows. It should be noted that we limited the period of diagnosis of diseases to the first 21 DIM, to standardize the period of disease development and treatment interventions and to be able to evaluate the lasting consequences of disease after its clinical treatment. Moreover, the period during the first 21 DIM is when dairy cows have the highest susceptibility to clinical disease and is commonly referred to as the end of the transition period ( 3 wk before through 3 wk after calving; LeBlanc, 2010; Sordillo, 2016). Accordingly, $30 \%$ of cows in the current study had at least one clinical disease during the first 21 DIM, and they represented $66 \%$ of all cows diagnosed with at least one clinical disease through 305 
DIM and $55 \%$ of all clinical cases diagnosed through 305 DIM. These proportions are similar to those previously reported by others (Santos et al., 2010; Dubuc et al., 2011a; Hostens et al., 2012; Ribeiro and Carvalho, 2017) and re-emphasize the relevance of postpartum health problems in dairy farms.

Instead of looking at the consequences of individual types of disease, we decided to look at postpartum clinical disease in a holistic way to better quantify the overall effect of postpartum health on long-term productivity and survival of dairy cows. The current study clearly demonstrates that consequences of postpartum clinical disease are not limited to the period of clinical illness but are extended to periods after the clinical resolution of the disease. In general, the long-term consequences of disease are more difficult to measure and are often overlooked by dairy managers. Nonetheless, they account for the majority of the associated costs. For instance, through 305 DIM, milk yield was reduced by approximately $4 \%$, pregnancy rate was reduced by $19 \%$, and culling rate was increased by $95 \%$ in cows diagnosed with at least a single postpartum clinical disease. Of those differences, the first 21 DIM accounted for only $24 \%$ of the total differences in 305-d milk production, $0 \%$ of the total differences in reproduction, and $36 \%$ of the total differences in culling. In agreement with our findings, Rollin et al. (2015) reported that long-term losses of milk production, reproduction, and culling accounted for $71.1 \%$ of all costs associated with clinical mastitis that occur during the first 30 DIM. It is important to mention that our studies were performed in a single large dairy herd, and, therefore, replication of our studies in other herds will be important to validate our findings in a larger population of dairy cows.

Measuring the effects of clinical disease on future milk production is challenging, and the results are often conflicting (Fourichon et al., 1999). For most cases, a reduction in daily milk yield is observed when cows are clinically ill, and a gradual increase in milk yield is observed with clinical resolution of the disease (Fourichon et al., 1999). In contrast, it is unknown whether milk production after clinical resolution returns to pre-disease levels, because one cannot predict how milk production would have progressed in the same individual without the development of a clinical disease. Moreover, establishment of a healthy control group is also difficult because of the variations in time of onset and duration of clinical problems. We attempted to overcome these challenges by enrolling a large number of cows in the study and considering the genomic potential for milk production. Our data indicate that disease during early lactation influences milk production during the entire $305-\mathrm{d}$ period, and reduced lactation performance is not

Table 4. Genomic PTA, predicted 305-d yields, and observed 305-d yields for milk, fat, and protein of cows with and without clinical disease during the first 21 DIM (ClinD21 and NoClinD21, respectively) enrolled in Study 2

\begin{tabular}{|c|c|c|c|}
\hline Item & NoClinD21 & ClinD21 & $P$-value \\
\hline Cows, n (\%) & $1,852(76.7)$ & $563(23.3)$ & - \\
\hline \multicolumn{4}{|c|}{ Genomic EBV,${ }^{1} \mathrm{~kg}$} \\
\hline Milk & $891.8 \pm 10.2$ & $881.4 \pm 18.6$ & 0.63 \\
\hline Fat & $32.2 \pm 0.2$ & $31.8 \pm 0.6$ & 0.46 \\
\hline Protein & $42.6 \pm 0.4$ & $42.6 \pm 0.8$ & 0.92 \\
\hline \multicolumn{4}{|c|}{$305-\mathrm{d}$ milk yield, ${ }^{2} \mathrm{~kg}$} \\
\hline Predicted & $11,281 \pm 5.1$ & $11,276 \pm 9.3$ & 0.63 \\
\hline Observed & $11,212 \pm 44.0$ & $10,867 \pm 71.6$ & $<0.01$ \\
\hline Difference $^{3}$ & $-59.8 \pm 41.8$ & $-402.2 \pm 67.4$ & $<0.01$ \\
\hline \multicolumn{4}{|c|}{$305-\mathrm{d}$ fat yield ${ }^{2} \mathrm{~kg}$} \\
\hline Predicted & $408.4 \pm 0.1$ & $408.2 \pm 0.3$ & 0.46 \\
\hline Observed & $400.9 \pm 1.7$ & $391.1 \pm 2.8$ & $<0.01$ \\
\hline Difference $^{3}$ & $-7.2 \pm 1.7$ & $-16.6 \pm 2.7$ & $<0.01$ \\
\hline \multicolumn{4}{|c|}{$305-\mathrm{d}$ protein yield, ${ }^{2} \mathrm{~kg}$} \\
\hline Predicted & $344.7 \pm 0.2$ & $344.8 \pm 0.4$ & 0.92 \\
\hline Observed & $342.3 \pm 1.2$ & $332.0 \pm 1.9$ & $<0.01$ \\
\hline Difference $^{3}$ & $-1.0 \pm 1.2$ & $-11.1 \pm 1.9$ & $<0.01$ \\
\hline
\end{tabular}

${ }^{1}$ Calculated based on information of SNP obtained from a low-density panel (Clarifide, Zoetis Genetics, Kalamazoo, MI).

${ }^{2}$ Predicted yields of milk, fat, and protein were calculated by the sum of the genomic PTA and the average of the observed values. Observed values represent the total milk production in $305 \mathrm{~d}$, which was measured at each milking by the milking system (SmartDairy meter, Boumatic, Madison, WI). The difference between observed and predicted values was calculated for each cow and analyzed statistically to determine the association with ClinD21.

${ }^{3}$ Adjusted means of the difference between observed and predicted yields. 
associated with differences in the genetic potential to produce milk. In fact, genomic predictions of 305-d yields were more accurate in cows that did not have postpartum clinical disease, because disease causes detrimental deviations from the genomic potential of the cow. Moreover, recent studies evaluating data from a large number of cows seem to be consistent in reporting long-term consequences of uterine disease (Dubuc et al., 2011a), mastitis (Rollin et al., 2015), and metabolic problems (Hostens et al., 2012) on lactation performance of dairy cows.

Our milk production data could be split into 3 periods: (1) the first $3 \mathrm{wk}$, which represent the period of clinical disease diagnose for formation of groups of interest; (2) wk 4 to 14, which covers the period when most cows reach peak of production; and (3) wk 15 to 44 , which represents the period after peak of production. These periods accounted for 24, 47, and 29\%, respectively, of the total differences in 305-d milk production between cows that had or did not have clinical disease by 21 DIM. Based on weekly averages of daily milk yield, it is clear that differences in milk production between these 2 groups of interest were less over time, which is likely a result of 2 factors: (1) a true reduction of the effect of postpartum clinical disease on milk production, and (2) a confounding effect of culling of low-producing cows. Cows that had postpartum clinical disease were more likely to be culled by 305 DIM and were culled earlier and, therefore, do not contribute fully to milk production data. Milk production is an important determinant of culling decisions, and, most likely, cows with the greatest effect of clinical disease and, consequently, the lowest milk production, were culled. Thus, the long-term effects of clinical disease on milk production are actually underestimated, especially in later stages of lactation, in which culled cows have a lower contribution to the data.

The mechanism by which early postpartum clinical disease affects lactation performance is uncertain and might differ according to the type of disease. Clinical mastitis, for instance, may cause damage in the milk-secretory epithelium of the mammary gland and increase the rate of cell death (Capuco et al., 2003), which might have long-term consequences on lactation performance (Santos et al., 2004). Nonetheless, our data suggest that disease that occurs outside the mammary gland had similar effects on lactation performance and had additive detrimental effects when combined with clinical mastitis. Thus, physiological responses to an infection or injury in tissues outside the mammary gland might also have long-term effects on the activity of epithelial cells of the mammary gland or on the rate of cell proliferation and apoptosis. In fact, systemic inflammation is negatively associated with milk production during early lactation (Bionaz et al., 2007; Bertoni et al., 2008; Carpenter et al., 2016). In addition to inflammation, transient changes in nutrient supply to the mammary gland epithelium caused by altered partition of nutrients (Kvidera et al., 2017), feeding behavior (Fogsgaard et al., 2015), or even feed efficiency caused by reduced feed intake (Zhang et al., 2013), could have long-term implications on the biology of epithelial cells of the mammary gland in cows with postpartum clinical disease. In fact, management changes at early stages of lactation, such as increased milk frequency (Hale et al., 2003) and alternative feeding strategies or feed restriction (Jørgensen et al., 2016) are known to have long-term consequences as regards lactation performance, and similar mechanisms might be associated with postpartum clinical disease.

The association between the general incidence of postpartum clinical disease and reproduction of dairy cows has been described previously (Santos et al., 2010; Ribeiro et al., 2013, 2016; Ribeiro and Carvalho, 2017). Nonetheless, previous analyses were limited to the first postpartum breeding. Here, we evaluated the consequences of clinical disease in reproductive performance beyond the first breeding. All reproduction data through 305 DIM were summarized and modeled according to incidence of clinical disease during the first 21 DIM. Although no differences in time to first breeding were observed, cows that had clinical disease had a $19 \%$ reduction in pregnancy rate through 305 DIM, based on pregnancy diagnosis $45 \mathrm{~d}$ after breeding. When only pregnancy that resulted in a new calving was considered, then accounting for pregnancy losses, the effect of clinical disease during the first 21 DIM was even greater, and pregnancy rate through 305 DIM was $31 \%$ lower. Differences in pregnancy rate were present even when cows that became pregnant after the first breeding were excluded from the analyses, which suggests that long-term effects of disease extend to periods beyond the first postpartum breeding. Other researchers have demonstrated differences in reproductive performance throughout lactation according to incidence of specific clinical problems such as uterine diseases (Dubuc et al., 2011b), clinical mastitis (Santos et al., 2004), and lameness (Bicalho et al., 2007).

Delaying the time of the first postpartum breeding by extending the VWP has been considered a strategy to avoid the negative effects of early postpartum clinical disease on reproduction. However, this strategy has not been validated. To estimate the duration of the detrimental effects of clinical disease on fertility, we evaluated the outcomes of all breedings performed through 305 DIM. Determining the duration of detri- 
mental effects could have implications for management decisions regarding breeding and culling strategies. Interestingly, we observed that clinical disease during the first 21 DIM had detrimental effects on pregnancy per breeding only in breedings performed before 150 DIM, suggesting that long-term effects of clinical disease on reproduction would last less than 5 mo. In contrast, when calving per breeding was evaluated, difference according to health status at the early postpartum was observed in breedings performed through 200 DIM. The difference was caused by the greater incidence of pregnancy losses after d 45 in cows that had clinical disease during the first 21 DIM. The greater incidence of late pregnancy loss was observed in all DIM range categories through 305 DIM, indicating that postpartum clinical disease influences pregnancy survival even 7 to 10 mo after clinical resolution of the disease. Thus, our data do not support the idea of delaying the first breeding to minimize the consequences of postpartum disease on reproduction.

The mechanism by which fertility of dairy cows is affected by postpartum health status is not completely understood. Data from first postpartum breeding suggest a combination of reduced oocyte quality and impaired uterine environment (Ribeiro et al., 2016). Inflammatory mediators are likely responsible for the reduction in oocyte quality (Bromfield et al., 2015; Roth, 2018). Impaired uterine environment, however, could be a result of long-term consequences of disease on cow metabolism and consequently on uterine histotroph composition, which is critical for conceptus development, implantation, and survival (Ribeiro and Carvalho, 2017; Ribeiro, 2018). Histotroph is secreted by epithelial cells of the endometrium into the uterine lumen and is used for nourishment and cell signaling by the developing conceptus (Spencer and Bazer, 2004). Similarities between the mammary gland and endometrial epithelia exist (Spencer and Bazer, 2004), and, therefore, the discussion above regarding the potential effects of diseases on cell biology of epithelial cells of the mammary gland is also valid for the endometrial epithelial cells. More research, however, is needed to fully understand the consequences of clinical disease and its associated physiological changes on cell biology and function of the uterus and the mammary gland.

With important detrimental consequences for lactation and reproductive performances, the large effect of postpartum clinical disease on survival of cows does not come as a surprise. The proportion of cows culled by 305 DIM increased from $23 \%$ in cows without clinical disease during the first 21 DIM to $36 \%$ and $54 \%$ in those diagnosed with a single and multiple clinical diseases, respectively. Moreover, culling rate through
305 DIM was increased by 95 and $306 \%$ in the latter 2 groups, respectively. Both deaths and sales of cows contributed significantly to the overall difference in culling between cows that had or did not have clinical disease. Moreover, differences in culling rate were also present when culling that occurred by 21 DIM was excluded from analyses, suggesting that postpartum clinical disease influences the long-term survival of dairy cows. It is worth mentioning that, similar to milk production, the effect of clinical disease on culling is also underestimated because a significant number of cows are culled after 305 DIM, especially those with late-pregnancy losses. Culling has severe consequences for the economics of dairy herds and contributes importantly to the associated costs of postpartum clinical disease (Galligan, 2006; Overton and Fetrow, 2008; Rollin et al., 2015).

It is increasingly evident that dairy cow health during the early postpartum period has important implications for production, reproduction, and survival during the entire lactation. Nonetheless, postpartum clinical diseases are still prevalent in dairy herds worldwide. Thus, development and implementation of consistent management and breeding strategies that reduce incidence of postpartum clinical diseases and metabolic problems are critical for the sustainability of the dairy industry. In addition, good records of clinical diseases and development of decision-making tools based on health information could help managers to improve health and performance in dairy herds. This idea is not recent (Kelton et al., 1998), but, unfortunately, a large portion of dairy herds fail to keep consistent records of diseases, do not use or rarely use health information to make management decisions, and often underestimate the effects of cows' health in their production systems.

\section{CONCLUSIONS}

In 2 retrospective studies examining data from 7,500 lactating cows in a single herd, incidence of clinical disease during the first 21 DIM was substantial and was associated with long-term negative consequences in milk production, reproduction, and culling of dairy cows. Despite similar genetic potential to produce milk, the 305-d yields of milk were substantially lower in cows that had clinical disease during the first 21 DIM compared with those that did not have clinical disease. The reduction in milk production could not be explained only by the immediate losses that occur during clinical presentation of health problems, which indicates that consequences of clinical disease to lactation biology are extended to periods after clinical resolution. In fact, the peak of milk production was 
reduced and delayed in cows that had clinical disease during the first 21 DIM. Moreover, pregnancy rate was lower in cows that had clinical disease, which extended the interval from calving to pregnancy and reduced the proportion of cows that became pregnant by 305 DIM. Cows that had clinical disease presented reduced pregnancy per AI in breedings performed before 150 DIM, reduced calving per AI in breedings performed before 200 DIM, and greater pregnancy losses in all breedings through 305 DIM. As a consequence of health disorders per se, and the resulting reduction in lactation and reproductive performances, cows that had clinical disease early postpartum were more likely to be culled from the herd and left earlier than cows that did not have any clinical problem. In general, multiple clinical cases diagnosed during the first 21 DIM had additive detrimental effects on milk production, reproduction, and culling through 305 DIM. Our results indicate that the detrimental consequences of treated early-postpartum disease extend for months after resolution of clinical symptoms. Replication of our studies in multiple herds will be important to validate our research findings in a larger population of dairy cows.

\section{ACKNOWLEDMENTS}

The authors thank the owner and staff of North Florida Holsteins for giving access to their data and providing feedback regarding their management practices; Anderson Veronese and Achilles Vieira-Neto (University of Florida, Gainesville) for helping with data collection and organization; and Stephen LeBlanc (University of Guelph, Ontario, Canada) for providing valuable comments on this manuscript.

\section{REFERENCES}

Abramson, J. H. 2011. WINPEPI updated: Computer programs for epidemiologists, and their teaching potential. Epidemiol. Perspect. Innov. 8:1.

Bertoni, G., E. Trevisi, X. Han, and M. Bionaz. 2008. Effects of inflammatory conditions on liver activity in puerperium period and consequences for performance in dairy cows. J. Dairy Sci. 91:33003310. https://doi.org/10.3168/jds.2008-0995.

Bicalho, R. C., F. Vokey, H. N. Erb, and C. L. Guard. 2007. Visual locomotion scoring in the first seventy days in milk: Impact on pregnancy and survival. J. Dairy Sci. 90:4586-4591. https://doi .org/10.3168/jds.2007-0297.

Bionaz, M., E. Trevisi, L. Calamari, F. Librandi, A. Ferrari, and G. Bertoni. 2007. Plasma paraoxonase, health, inflammatory conditions, and liver function in transition dairy cows. J. Dairy Sci. 90:1740-1750. https://doi.org/10.3168/jds.2006-445.

Bromfield, J. J., J. E. Santos, J. Block, R. S. Williams, and I. M. Sheldon. 2015. Mechanisms linking infection and innate immunity in the female genital tract with infertility in dairy cattle. J. Anim. Sci. 93:2021-2033. https://doi.org/10.2527/jas.2014-8496.

Capuco, A. V., S.E. Ellis, S.A. Hale, E. Long, R.A. Erdman, X. Zhao, and M.J. Paape. 2003. Lactation persistency: Insights from mam- mary cell proliferation studies. J. Anim. Sci. 81(Suppl. 3):18-31. https://doi.org/2003.81suppl_318x.

Carpenter, A. J., C. M. Ylioja, C. F. Vargas, L. K. Mamedova, L. G. Mendonca, J. F. Coetzee, L. C. Hollis, R. Gehring, and B. J. Bradford. 2016. Hot topic: Early postpartum treatment of commercial dairy cows with nonsteroidal antiinflammatory drugs increases whole-lactation milk yield. J. Dairy Sci. 99:672-679. https://doi .org/10.3168/jds.2015-10048.

Dubuc, J., T. F. Duffield, K. E. Leslie, J. S. Walton, and S. J. LeBlanc. 2011a. Effects of postpartum uterine diseases on milk production and culling in dairy cows. J. Dairy Sci. 94:1339-1346. https://doi .org/10.3168/jds.2010-3758.

Dubuc, J., T. F. Duffield, K. E. Leslie, J. S. Walton, and S. J. LeBlanc. 2011b. Randomized clinical trial of antibiotic and prostaglandin treatments for uterine health and reproductive performance in dairy cows. J. Dairy Sci. 94:1325-1338. https://doi.org/10.3168/ jds.2010-3757.

Fogsgaard, K. K., T. W. Bennedsgaard, and M. S. Herskin. 2015. Behavioral changes in freestall-housed dairy cows with naturally occurring clinical mastitis. J. Dairy Sci. 98:1730-1738. https://doi .org/10.3168/jds.2014-8347.

Fourichon, C., H. Seegers, N. Bareille, and F. Beaudeau. 1999. Effects of disease on milk production in the dairy cow: A review. Prev. Vet. Med. 41:1-35. https://doi.org/10.1016/S0167-5877(99)00035 -5 .

Galligan, D. 2006. Economic assessment of animal health performance. Vet. Clin. North Am. Food Anim. Pract. 22:207-227. https://doi .org/10.1016/j.cvfa.2005.11.007.

Hale, S. A., A. V. Capuco, and R. A. Erdman. 2003. Milk yield and mammary growth effects due to increased milking frequency during early lactation. J. Dairy Sci. 86:2061-2071. https://doi.org/10 .3168/jds.S0022-0302(03)73795-3.

Hostens, M., J. Ehrlich, B. Van Ranst, and G. Opsomer. 2012. Onfarm evaluation of the effect of metabolic diseases on the shape of the lactation curve in dairy cows through the MilkBot lactation model. J. Dairy Sci. 95:2988-3007. https://doi.org/10.3168/ jds.2011-4791.

Jørgensen, C. H., R. Spörndly, J. Bertilsson, and S. Østergaard. 2016 Invited review: Carryover effects of early lactation feeding on total lactation performance in dairy cows. J. Dairy Sci. 99:3241-3249. https://doi.org/10.3168/jds.2014-9043.

Kelton, D. F., K. D. Lissemore, and R. E. Martin. 1998. Recommendations for recording and calculating the incidence of selected clinical diseases of dairy cattle. J. Dairy Sci. 81:2502-2509. https://doi .org/10.3168/jds.S0022-0302(98)70142-0.

Kvidera, S. K., E. A. Horst, M. Abuajamieh, E. J. Mayorga, M. V. S. Fernandez, and L. H. Baumgard. 2017. Glucose requirements of an activated immune system in lactating Holstein cows. J. Dairy Sci. 100:2360-2374. https://doi.org/10.3168/jds.2016-12001.

LeBlanc, S. 2010. Monitoring metabolic health of dairy cattle in the transition period. J. Reprod. Dev. 56(Suppl.):S29-S35. https://doi .org/10.1262/jrd.1056s29.

NRC (National Research Council). 2001. Nutrient Requirements of Dairy Cattle. 7th rev. ed. Natl. Acad. Press, Washington, DC.

Overton, M., and F. Fetrow. 2008. Economics of postpartum uterine health. Pages 39-44 in Proc. 2008 Dairy Cattle Reproduction Council Annu. Meet., Omaha, NE. Dairy Cattle Reproduction Council, New Prague, MN.

Ribeiro, E. S. 2018. Lipids as regulators of conceptus development: Implications for metabolic regulation of reproduction in dairy cattle. J. Dairy Sci. 101:3630-3641. https://doi.org/10.3168/jds .2017-13469.

Ribeiro, E. S., and M. R. Carvalho. 2017. Impact and mechanisms of inflammatory diseases on embryonic development and fertility in cattle. Anim. Reprod. 14:589-600. https://doi.org/10.21451/1984 -3143-AR1002.

Ribeiro, E. S., G. Gomes, L. F. Greco, R. L. A. Cerri, A. Vieira-Neto, P. L. J. Monteiro Jr., F. S. Lima, R. S. Bisinotto, W. W. Thatcher, and J. E. P. Santos. 2016. Carryover effect of postpartum inflammatory diseases on developmental biology and fertility in lactating 
dairy cows. J. Dairy Sci. 99:2201-2220. https://doi.org/10.3168/ jds.2015-10337.

Ribeiro, E. S., F. S. Lima, L. F. Greco, R. S. Bisinotto, A. P. A. Monteiro, M. Favoreto, H. Ayres, R. S. Marsola, N. Martinez, W. W. Thatcher, and J. E. P. Santos. 2013. Prevalence of periparturient diseases and effects on fertility of seasonally calving grazing dairy cows supplemented with concentrates. J. Dairy Sci. 96:5682-5697. https://doi.org/10.3168/jds.2012-6335.

Rollin, E., K. C. Dhuyvetter, and M. W. Overton. 2015. The cost of clinical mastitis in the first 30 days of lactation: An economic modeling tool. Prev. Vet. Med. 122:257-264. https://doi.org/10.1016/j .prevetmed.2015.11.006.

Roth, Z. 2018. Reduction in oocyte developmental competence by stress is associated with alterations in mitochondrial function. J. Dairy Sci. 101: 3642-3654. https://doi.org/10.3168/jds.2017 -13389 .

Santos, J. E., R. L. Cerri, M. Ballou, G. Higginbotham, and J. Kirk. 2004. Effect of timing of first clinical mastitis occurrence on lactational and reproductive performance of Holstein dairy cows. Anim. Reprod. Sci. 80:31-45. https://doi.org/10.1016/S0378 $-4320(03) 00133-7$.

Santos, J. E. P., R. S. Bisinotto, E. S. Ribeiro, F. S. Lima, L. F. Greco, C. R. Staples, and W. W. Thatcher. 2010. Applying nutrition and physiology to improve reproduction in dairy cattle. Soc. Reprod. Fertil. Suppl. 67:387-403. https://doi.org/10.5661/RDR-VII-387.

Sheldon, I. M., J. Cronin, L. Goetze, G. Donofrio, and J. Schuberth. 2009. Defining postpartum uterine disease and the mechanisms of infection and immunity in the female reproductive tract in cattle. Biol. Reprod. 81:1025-1032. https://doi.org/10.1095/biolreprod 109.077370

Sordillo, L. M. 2016. Nutritional strategies to optimize dairy cattle immunity. J. Dairy Sci. 99:4967-4982. https://doi.org/10.3168/jds .2015-10354.

Spencer, T.E., and F.W. Bazer. 2004. Uterine and placental factors regulating conceptus growth in domestic animal. J. Anim. Sci. 82(E-Suppl.):4-13. https://doi.org/10.3168/jds.2017-13389.

Sumner, C. L., M. A. G. Von Keyserlingk, and D. M. Weary. 2018. Perspectives of farmers and veterinarians concerning dairy cattle welfare. Anim. Front. 8:8-13. https://doi.org/10.1093/af/vfx006.

Zhang, S., J. R. Aschenbach, D. R. Barreda, and G. B. Penner. 2013. Recovery of absorptive function of the reticulo-rumen and total tract barrier function in beef cattle after short-term feed restriction. J. Anim. Sci. 91:1696-1706. https://doi.org/10.2527/jas.2012 -5774 . 